\title{
Discurso do medo e as eleições presidenciais no Brasil em 2014
}

\author{
Discourse of fear and the presidential elections in Brazil in 2014
}

\author{
Vanderlei de Castro EZEQUIEL \\ Faculdade Cásper Líbero - Brasil \\ vander.ce@gmail.com
}

\begin{abstract}
Cómo citar este artículo: Ezequiel, Vanderlei de Castro (2016): "Discurso do medo e as eleições presidenciais no Brasil em 2014», Mediaciones Sociales, no 15, pp. 55-79. DOI: http://dx.doi.org/10.5209/MESO.54543
\end{abstract}

Recibido: 2 de septiembre de 2015.

Aceptado: 26 de mayo de 2016.

\section{RESUMO}

O objetivo deste trabalho é analisar o discurso do medo como estratégia de campanha eleitoral e refletir sobre a raiz conservadora desse discurso e sua apropriação por diferentes correntes políticas. Para tanto, foram utilizados os conceitos: origem do medo (Mira y Lopes), medo secundário (Bauman), racionalização do medo (Hobbes; Rancière; Adorno \& Horkheimer), conservadorismo (Bobbio), cultura do medo (Glassner) e espetacularização (Debord). A principal orientação teóricometodológica deste trabalho é a Análise de Discurso de linha francesa, entendendo o discurso político (Charaudeau) como enunciação de uma época. Conclui-se que, no atual contexto políticoeleitoral brasileiro o discurso do medo é utilizado de maneira generalizada pelos candidatos e partidos, independentemente do posicionamento ideológico. A utilização do discurso do medo nas eleições, intensificado pela cultura do medo presente na mídia, esvazia o debate político-eleitoral, espetacularizando a politica.

PALAVRAS-CHAVE: antiethos, discurso político, eleição, espetáculo, medo.

\section{ABSTRACT}

The objective of this study is to analyze the discourse of fear as an electoral campaign strategy and reflect on the conservative root of this speech and its appropriation by different political trends. For both aims, are used several concepts: source of fear (Mira \& Lopes), secondary fear (Bauman), 
rationalization of fear (Hobbes; Rancière; Adorno \& Horkheimer), conservatism (Bobbio), culture of fear (Glassner) and spectacle (Debord). The main theoretical and methodological orientation of this work comes from the French Discourse Analysis, understanding political discourse (Charaudeau) as an expression of an era. It concludes that, in the current Brazilian electoral context the discourse of fear is used extensively by candidates and parties, regardless of ideological positioning. The use of fear in the electoral discourse, intensified by this culture of fear in the media, empties the political and electoral debate, spectacularizing the politics.

KEYWORDS: antiethos, political discourse, election, spectacle, fear,

Sumário: 1. Introdução. 2. Fundamentação teórica. 2.1 Gigante negro: origem e manifestação do medo. 2.2 Razão e medo. 2.3 Pensamento conservador. 2.4 Mídia e cultura do medo. 2.5 Espetacularização da política. 3. Metodologia. 3.1 Análise de discurso. 3.2 Formação discursiva política eleitoral. 3.3 Ethos e entiethos. 4. Discurso do medo e eleições no Brasil. 5. O medo na disputa eleitoral de 2014. 6. Conclusão. Bibliografia.

\section{INTRODUÇÃO}

O não conhecimento de si mesmo é considerado uma das causas dos desentendimentos na história da humanidade. O homem, incerto dos seus próprios limites e recursos, desencontra-se nos diversos planos do meio social e tem o dom de estender a sua desventura ao meio que o cerca mais imediatamente. Em tempos de intensa disputa política, em que o ambiente social exibe o acirramento de posições ideológicas, faz-se necessária a investigação científica -objetiva e sistemática- da natureza humana e sua apropriação pelo discurso político eleitoral. Dentre as emoções humanas estimuladas durante as campanhas eleitorais está o medo.

Em todas as suas dimensões, o medo exerce um papel essencial na diversidade de jogos relacionais que caracterizam nossas trocas cotidianas. Para administrar essa complexa rede de interações, nas quais o outro pode assumir o papel de invasor, de perturbador, predador, o indivíduo necessita recorrer a autênticas estratégias de criatividade cognitiva, inventando formas socialmente aceitáveis de defesa e autoproteção. Nesse sentido, ante o sentimento do medo até a razão sucumbe.

Por outro lado, Hobbes (1979) afirma que o homem sempre teve medo de ser morto ou escravizado, sendo esse temor, a paixão que dá a palavra à razão. Dessa forma, é o medo que vai obrigar os homens a fundarem um estado social, constituindo também a autoridade política. A paz e a segurança tornam-se, assim, uma construção coletiva e consensual. Não havendo nenhuma exigência moral, o medo mostra-se maior do que a vaidade, e os homens concordam em abdicar todos os seus poderes em favor de um soberano. 
Muitos pesquisadores e cientistas políticos afirmam que o "medo não elege". Entretanto, esse é um discurso recorrente em campanhas eleitorais No período eleitoral, candidatos e partidos políticos investem em elementos de diferenciação no enfrentamento da concorrência, cada vez mais acirrada, pelo voto. A principal estratégia é desenvolver uma imagem positiva (ethos) do candidato e do partido junto à população. Por outro, o ataque aos adversários também é amplamente utilizado, empregando, muitas vezes, o discurso do medo para desconstruir e macular a imagem, criando um antiethos dos oponentes.

O objetivo deste trabalho é analisar o discurso do medo como estratégia de campanha eleitoral. Especificamente, pretende-se identificar a utilização do discurso do medo para construção do ethos dos candidatos e antiethos dos adversários e sua apropriação por diferentes correntes político/ideológicas, durante as eleições para Presidente da República do Brasil em 2014. A principal orientação metodológica será a Análise de Discurso da linha francesa.

O trabalho inicia-se apresentando os conceitos: origem do medo (Mira y Lopes), medo secundário (Bauman), racionalização do medo (Hobbes; Rancière; Adorno \& Horkheimer), conservadorismo (Bobbio), cultura do medo (Glassner) e espetacularização (Debord). Segue com a apresentação da metodologia da Análise de Discurso de linha francesa -formação discursiva, ethos e antiethos-. Em seguida, apresenta o objeto -fala dos principais candidatos durante a campanha eleitoral de 2014- e analisa as sequências discursivas selecionadas. Finaliza com uma análise crítica do discurso do medo nas eleições.

\section{FUNDAMENTAÇ̃̃O TEÓRICA}

\subsection{Gigante negro: origem e manifestação do medo}

Especializada modalidade de o organismo reelaborar as informações e enfrentar a realidade, como afirma a psicóloga Maria Rita Ciceri (2004: 8), o medo é "um autêntico 'sistema defensivo', que medeia nossa ação sobre o mundo, tornando-a mais segura e eficaz". Para a psicanalista Maria Rita Kehl (2007: 89), o medo é um sentimento vital que protege o indivíduo dos riscos da morte, "o medo pode ser provocado pela percepção de nossa insignificância perante o universo, da fugacidade da vida, das vastas zonas sombrias do desconhecido". O medo, segundo a filósofa Marilena Chauí (2009), é uma paixão humana que, articulada a outras paixões, forma um "sistema do medo" que determina a maneira de sentir e de pensar de todos que a ele são submetidos. Já o sociólogo Zygmunt Bauman (2006: 9) afirma que "o medo é um sentimento conhecido de toda criatura viva". Enquanto Adauto Novaes (2007: 20), jornalista, descreve o medo como "um sentimento negativo presente causado pela 
ideia de um sentimento negativo futuro ou potencial". Assim, o medo conteria algo de incerto, um desconforto em relação ao que pode vir a causar sofrimento.

De acordo com o psiquiatra Emilio Mira y López (1996: 6), existem três emoções primárias, "nas quais se encontra toda a gama de reflexos e deflexos de fuga, agressão e fusão possessiva". Essas emoções são conhecidas como Medo, Ira e Afeto (ou Amor) ou, como se refere metaforicamente o autor, respectivamente: gigante negro, gigante rubro e gigante rosa.

No estado primitivo, o homem "selvagem" -Homo Natura- move-se principalmente por impulsos de preservação e de expansão do seu ser. São complexos dispositivos defensivo-ofensivos e também de procriação, reconhecidos como instintos de conservação e de reprodução, revelando-se "primeiro sob a forma de leves 'desejos', depois, de claras 'ânsias' e, mais tarde, se não são a tempo satisfeitos, de imperiosas e incontidas 'necessidades' de fuga, de ataque ou de posse" (Mira y López, 1996: 5).

O medo representa uma emoção extraordinariamente complexa, pois acha-se integrado pela combinação de vários processos que foram surgindo ao longo da evolução biológica. Pode ser definido como um estado, não da mente, mas do sistema neuroendócrino, constituindo uma raiz biológica primitiva do fenômeno emocional,

«Por isso, em qualquer protozoário podemos surpreender a inatividade (cessação de atividades) em resposta ao impacto excitante nociceptivo, em um vertebrado já somos capazes de notar essa mesma inatividade em previsão do possível ou provável dano. E isto -acuse-se ou não em forma subjetiva- é propriamente o Medo» (Mira y López, 1996: 10-11).

Para Mira y López, o surgimento do gigante negro confunde-se com a própria origem da vida. A evolução biológica preparou o sistema nervoso humano para que a ocorrência de um forte medo preceda qualquer outra emoção na mente e no corpo. Maria Rita Ciceri (2004: 11-12) confirma: "O medo é nossa emoção mais antiga".

Inerente à natureza humana, constituindo-se numa defesa essencial contra os perigos, o medo é indispensável reflexo que auxilia ao organismo escapar provisoriamente à morte: sem ele, nenhuma espécie teria sobrevivido. Para Delumeau, o termo medo, no sentido estrito (individual):

«é uma emoção-choque, frequentemente precedida de surpresa, provocada pela tomada de consciência de um perigo presente e urgente que ameaça, cremos nós, nossa conservação. Colocado em estado de alerta, o hipotálamo reage mediante mobilização global do organismo, que desencadeia diversos tipos de comportamentos somáticos e provoca sobretudo modificações endócrinas» (Delumeau, 2009: 30).

Dessa forma, compartilhamos com os animais o chamado "medo original", o medo da morte. Um medo inato, endêmico, graças ao instinto de sobrevivência programado em todas espécies no curso da evolução. Delumeau (2007: 41) entende que o 
medo da morte é o medo fundamental: "Todos os medos contêm, em graus diferentes, essa apreensão fundamental; e, portanto, o medo não desaparecerá da condição humana ao longo de nossa peregrinação terrestre". Entretanto, somente os seres humanos, afirma Bauman (2006: 10), convivem com a consciência da inevitabilidade da morte: "e assim também enfrentamos a apavorante tarefa de sobreviver à aquisição desse conhecimento - a tarefa de viver com o pavor da inevitabilidade da morte e apesar dele". Maria Rita Kehl complementa:

«O homem pode localizar as razões de seu medo pelo uso da linguagem: o acesso ao simbólico torna a morte pensável (embora nunca totalmente simbolizável). O medo, entre os humanos, pode resultar de uma operação simbólica» (Kehl, 2007: 93).

Dentre os estímulos, objetos ou "agentes" do medo existem aqueles fatores motivantes que, por seu caráter de máxima difusão em grandes círculos culturais e sua persistência através do tempo devem ser considerados como principais estímulos fobígenos, Mira y López (1996) destaca: os cataclismos naturais; a dor; os sofrimentos morais; a morte; as enfermidades; a solidão; a vida; os instintos; a guerra; a revolução, sendo esta última mais temível que a guerra, pois nesta sabemos onde está o inimigo, enquanto na revolução ninguém pode prever de onde partirá o golpe: do vizinho, do amigo, do irmão.

Existem também os estímulos que causam medo e surgem com a interação social, resultante da evolução humana. No convívio em sociedade surge a necessidade de estar-se preparado para enfrentar os sustos perante qualquer estímulo intenso ou novo, oriundo da interação social.

Além do "medo original", o medo da morte natural a todas as espécies, o ser humano conhece ainda o chamado "medo secundário". Constituído social e culturalmente, esse medo "derivado" orienta o comportamento humano, reformando sua percepção do mundo e as expectativas que orientam suas escolhas comportamentais, mesmo na ausência de uma ameaça imediatamente presente. Bauman (2006: 9) considera o medo secundário como um "rastro" de uma experiência de enfrentamento de ameaça real, direta, vivida pelo indivíduo, "um resquício que sobrevive ao encontro e se torna um fator importante na modelagem da conduta humana mesmo que não haja mais uma ameaça direta à vida ou à integridade". Essa estrutura mental pode ser melhor descrita como um sentimento de ser suscetível ao perigo, uma sensação de insegurança, reação aos "perigos" que nos rodeiam e que podem se concretizar sem aviso prévio. Também a sensação de vulnerabilidade atormenta o indivíduo, consciente da necessidade de fuga/defesa, caso o perigo se concretize, sendo esse tormento mais dependente da maior ou menor confiança nos recursos próprios de defesa às possíveis ameaças. Nesse sentido, Bauman entende que, 
«Uma pessoa que tenha interiorizado uma visão de mundo que inclua a insegurança e a vulnerabilidade recorrerá rotineiramente, mesmo na ausência de ameaça genuína, às reações adequadas a um encontro imediato com o perigo; o "medo derivado" adquire a capacidade da autopropulsão» (Bauman, 2006: 9).

Pode-se afirmar que, a variedade moderna de insegurança é marcada, principalmente, pelo medo da maleficência humana e dos malfeitores humanos. A suspeita de motivos malévolos da parte de determinados indivíduos -ou mesmo grupos ou categorias específicos- desencadeiam a insegurança moderna. Esta é alimentada, frequentemente, também pela recusa em confiar na fidelidade, constância e dedicação do outro, "uma recusa que é quase inevitavelmente seguida de nossa indisposição em construir uma camaradagem sólida, durável e portanto confiável" (Bauman, 2006: 171). Assim, o medo é capaz de impulsionar-se e intensificar-se por si mesmo, adquirindo uma lógica de desenvolvimento própria, dispensando, em muitos casos, estímulos adicionais para crescer e difundir-se: "O medo nos estimula a assumir uma ação defensiva, e isso confere proximidade, tangibilidade e credibilidade às ameaças, genuínas ou supostas, de que ele presumivelmente emana" (Bauman, 2006: 173). Na atualidade há um "desacoplamento" entre as ações de defesa inspiradas pelo medo e os temores existenciais que causaram esse medo, neste sentido, ocorre

«o deslocamento dos medos, das brechas e fissuras das defesas humanas em que o "destino" é produzido e incubado para áreas da vida amplamente irrelevantes em relação à verdadeira fonte de ansiedade, mas em vez disso - consoladoramente - visíveis e alcançáveis» (Bauman, 2006: 174).

Dessa forma, evidentemente, não importa a quantidade de esforço investida nas áreas para as quais o medo foi deslocado, pois isto não neutralizará ou bloqueará as verdadeiras fontes do medo, tornando a ação impotente para diminuir a ansiedade original.

\subsection{Razão e medo}

Thomas Hobbes -em seu clássico Leviatã- parte de um construto teórico: "estado de natureza", utilizado como metáfora para explicar como seria a vida dos homens se eles não vivessem em sociedade. Assim, os homens em estado de natureza não estão submetidos a qualquer ordenamento ou instituição superior a si, sendo todos iguais, tanto em força física como em espírito. Ou seja, igualmente aptos a matar e, por isso mesmo, vivendo a ameaça de um estado caótico, de ausência de regras comuns, de anomia total, tendo como expressão máxima a guerra de todos contra todos. Devido às paixões humanas: insegurança, cupidez, desconfiança, e o conflito generalizado -caracterizado por um contexto de ausência de um poder capaz de estabelecer a ordem nas leis e nos valores, definindo o que é certo e o que é errado e garantir o cumprimento da lei-, a 
situação de convívio coletivo torna-se inviável e a paz social não é possível. Em contrapartida,

«As paixões que fazem os homens tender para a paz são o medo da morte, o desejo daquelas coisas que são necessárias para uma vida confortável, e a esperança de consegui-las através do trabalho. E a razão sugere adequadas normas de paz, em torno das quais os homens podem chegar a acordo» (Hobbes, 1979: 77).

Assim, ao tomar consciência do perigo comum em que se encontram, os indivíduos teriam tomado a decisão racional de saírem do estado natural, entrando no estado civil. Torna-se necessária, diz Hobbes, a criação de um poder indivisível que seja capaz de "conter o que há de mais perigoso nas relações humanas", institui-se, então, o poder do Estado, que receberá o nome bíblico de Leviatã. E no centro dessa metáfora do nascimento do Estado encontra-se o medo, especificamente, o medo da morte violenta, que para Hobbes é o que permite a saída da barbárie e entrada na civilização. Esse medo, produtor de racionalidade, parte de um impulso que, ao colocar em risco um bem essencial -a vida- estimula os indivíduos a ultrapassarem suas divergências para fundar uma ordem política, garantindo a sobrevivência de todos.

O medo também foi abordado pelos autores da Escola de Frankfurt. Já no início da obra Dialética do Esclarecimento, Adorno e Horkheimer indicam a essência do conceito de "esclarecimento": "No sentido mais amplo do progresso do pensamento, o esclarecimento tem perseguido sempre o objetivo de livrar os homens do medo e investi-lo na posição de senhores" (Adorno \& Horkheimer, 1985: 19). Dessa forma, o esclarecimento tem origem no medo, e também como reação a este sentimento.

«Do medo o homem presume estar livre quando não há mais nada de desconhecido. É isso que determina o trajeto da desmitologização e do esclarecimento, que identifica o animado ao inanimado, assim como o mito identifica o inanimado ao animado. O esclarecimento é a radicalização da angústia mítica. A pura imanência do positivismo, seu derradeiro produto, nada mais é que um tabu, por assim dizer, universal. Nada mais pode ficar de fora, porque a simples ideia do "fora" é a verdadeira fonte da angústia» (Adorno \& Horkheimer, 1985: 29).

Um dos sentidos presente neste conceito é o do medo perante todos aqueles processos e forças naturais que permanecem ainda não dominados, incontroláveis e imprevisíveis. Ou seja, o medo diante de tudo o que ainda não se curvou ao domínio técnico do homem e que, por isso mesmo, o faz sentir-se indefeso, impotente, pois o agente fobígeno apresenta-se como ameaça à conservação da vida humana. Adorno e Horkheimer procuram estabelecer a gênese e a própria necessidade de uma racionalidade instrumental voltada para a dominação da natureza como reação ao sentimento do medo. A esse respeito, dizem os autores,

«Concretiza-se assim o mais antigo medo, o medo da perda do próprio nome. Para a civilização, a vida no estado natural puro, a vida animal e vegetativa, constituía o perigo 
absoluto. Um após o outro, os comportamentos mimético, mítico e metafísico foram considerados como eras superadas, de tal sorte que a ideia de recair neles era associada ao pavor de que o eu revertesse à mera natureza, da qual se havia alienado com esforço indizível e que por isso mesmo infundia nele indizível terror» (Adorno \& Horkheimer, 1985: 42).

Segundo os autores, o homem presume estar livre do medo quando não há mais nada de desconhecido. Dessa forma, o esclarecimento só pode declarar ter vencido definitivamente o medo quando o esquema da dedutibilidade universal tiver compreendido "sem resto" todo o real, ou seja, a identificação da realidade com aquilo que pode ser apreendido pela matemática e a eliminação de toda a transcendência.

Para Rancière, existem três maneiras de pensar a relação da razão com o medo. A primeira constitui a atitude razoável sobre o medo, ou seja, a apreensão do perigo: "a razão está em não passar para o lado do desconhecido" (Rancière, 2007: 59). A segunda, aquela que toma por critério a própria rejeição do medo, ou melhor, a rejeição da submissão ao desconhecido. Não existe conduta a tomar sobre o desconhecido, pois, a conduta somente se realiza naquilo que sabemos. Neste sentido, o medo só é bom para uma coisa: "povoar as regiões ignorantes de criaturas imaginárias pelas quais em compensação se ordena, com sabedoria suprema, que tenham medo e que não procurem saber por quê" (Rancière, 2007: 59). Por último, a terceira atitude, aquela que coloca a razão para lidar com as paixões em geral e, em particular com o medo, paixão que ameaça ao mesmo tempo "o movimento do presente em direção ao futuro e a relação do semelhante ao semelhante, a conduta das ações em direção a seus fins e a relação entre os membros de uma comunidade" (Rancière, 2007: 59).

\subsection{Pensamento conservador}

No senso comum, explora-se a ideia de que os indivíduos são conservadores por natureza -já que, nas relações humanas e sociais, tendem a rejeitar mudanças, resistindo ao novo-. Neste sentido, o conservadorismo, mais do que uma doutrina política, estaria incrustado na essência do ser humano.

De acordo com Bobbio (1995: 242), na ciência política o termo conservadorismo "designa ideias e atitudes que visam a manutenção do sistema político existente e dos seus modos de funcionamento, apresentando-se como contraparte das forças inovadoras".

Historicamente, o processo de secularização e laicização do pensamento político e social europeu surge com a ascensão da burguesia. A emergência do homem burguês (do indivíduo), do individualismo e do sujeito autônomo capaz de, por sua ação, transformar a sua realidade e fazer a história, inaugura a modernidade. Em contrapartida, o pensamento conservador expressa uma alternativa à modernidade e ao 
pensamento progressista. A Revolução Francesa é um marco fundamental e linha divisória do pensamento político, seja conservador ou progressista.

Compreendido também como ideologia -corpo ideias com conteúdo prescritivo-, o conservadorismo presente em Edmund Burke (1729-1797) surge para contrapor-se: ao iluminismo e às ideias revolucionárias que pregavam a possibilidade de aperfeiçoar a vida humana por meio das transformações sociais e políticas; à crença no triunfo da razão humana; ao descaso e depreciação da autoridade, do privilégio, da hierarquia e da tradição. Para Bobbio,

«O conservadorismo surge só como resposta necessária às teorias que, a partir do século XVIII, se distanciaram da visão antropológica tradicional, para reivindicar para o homem a possibilidade, não só de melhorar o próprio conhecimento e seu domínio sobre a natureza, como também de alcançar, por meio de ambos, uma autocompreensão cada vez maior e, consequentemente, a felicidade [...] isto implicava o rompimento com a tradição, o que provocou fendas na consciência europeia, quer a nível cultural, quer a nível político» (Bobbio, 1995: 243).

O conservadorismo também é interpretado como uma disposição da mente ou do hábito. Neste sentido, conservar seria intrínseco à natureza humana -hostil à mudançaque desconfia de tudo que é desconhecido (novo), preferindo confiar na experiência e na tradição, em lugar do pensamento abstrato e raciocínio teórico. Assim, o ser humano teria uma disposição natural em preferir os hábitos e ferramentas experimentadas e ligadas à tradição. Em termos políticos, significa preferir sistemas e instituições imperfeitas já estabelecidas ao inusitado, exibindo um receio de mudar e uma disposição de conservar a ordem, a tradição.

A disposição conservadora -nata no indivíduo-, impele a atitudes reativas sempre que uma ameaça ronda suas instituições e valores mais caros. Dessa forma, a reação conservadora, "longe de ser apenas uma expressão primitiva do medo e repúdio em face da inovação revolucionária (ou reacionária), será informada por certos princípios gerais que determinam o tipo de reação conservadora" (Coutinho, 2014: 33).

Há uma disposição natural em conservar aquilo que se estima: pessoas, coisas, lugares. Para o filósofo inglês Michael Oakeshott, existe uma disposição conservadora ${ }^{1}$ no indivíduo, que antecede a "ideologia" ou "doutrina". Dessa forma, o conservadorismo seria uma forma de ser e agir que levaria o conservador a preferir aquilo que já está disponível, ao invés de desejar ou buscar algo novo. Assim, um indivíduo de disposição conservadora tende a valorizar primeiro os confortos do presente à qualquer alternativa hipotética, pelo simples fato de serem reais, tangíveis e não uma possibilidade futura que ainda não se concretizou.

1 Formulação de Michael Oakeshott no clássico ensaio "On Being Conservative" ["Sobre ser conservador"] em 1956. 
«Ser conservador, então, é preferir o familiar ao desconhecido, o testado ao nunca testado, o fato ao mistério, o atual ao possível, o limitado ao ilimitado, o próximo ao distante, o suficiente ao abundante, o conveniente ao perfeito, o riso presente à felicidade utópica» (Oakeshott apud Coutinho, 2014: 21).

Manifestação do pragmatismo político, o conservadorismo se adapta, absorvendo o ethos político, econômico e cultural dominante. Prevalece, assim, a legitimação do que mantém a ordem, mesmo que seja adotando ideias que sempre combateu. Dessa forma, uma ideologia revolucionária, integrada à ordem burguesa ou na medida em que consolida uma nova ordem política social, tende a se tornar conservadora e pragmática. Esta alternância de posição tratar-se-ia apenas de estratégia de sobrevivência,

"Os conservadores defendem a ordem existente, qualquer que seja a sua natureza política, contra o caos e a reforma. Nesta perspectiva, podemos falar em esquerda conservadora: qualquer ordem institucional tende a ser conservadora. Trata-se de garantir a permanência da situação a partir da posição que os agentes políticos ocupam» (Silva, 2010: 55).

Nesse sentido, o conservadorismo apresenta uma dimensão existencial que é anterior a qualquer ideologia política. Entretanto, Coutinho lembra que a disposição conservadora e o conservadorismo político nem sempre coexistem no mesmo indivíduo. Algumas pessoas, mesmo possuindo uma disposição conservadora, não exibem, necessariamente, uma preferência política pelo conservadorismo: "E o inverso também sucede: pessoas de disposição mais radical nas suas personalíssimas condutas que, politicamente falando, subscrevem posições conservadoras" (Coutinho, 2014: 23-24).

\subsection{Mídia e cultura do medo}

A mídia, na atualidade, tornou-se um dos principais fatores responsáveis pela formação cultural dos indivíduos. Para Thompson (1998: 187), a mídia -tanto a impressa quanto a eletrônica- é a grande responsável pela formação do Eu (self), além disso, "ao mesmo tempo, contudo, os indivíduos se tornam cada vez mais dependentes de um leque de instituições e sistemas sociais que Ihes proporcionam os meios -tanto materiais quanto simbólicos- de construção de seus projetos de vida".

Definida como o conjunto de meios ou ferramentas utilizados para a transmissão de informações ao público (rádio, televisão, internet, etc.), a mídia poderia assumir um importante papel na formação de uma sociedade menos conflituosa. Entretanto, num contexto capitalista, a mídia serve principalmente como mecanismo de conservação do status quo, fomentando o consumo, ditando modas e regras, atuando, principalmente, sob interesses estritamente comerciais. Ao utilizar expedientes sensacio- 
nalistas, normalmente dando conta de fatos negativos, como crimes e catástrofes para chamar a atenção do público e obter o lucro, a mídia dissemina o sentimento de insegurança na sociedade, estimulando a cultura do medo.

O autor norte-americano Barry Glassner -em seu livro Cultura do Medo- afirma que os jornalistas, ao utilizarem expressões apelativas e sensacionalistas, aumentam a sensação de medo na sociedade. Para o autor, os jornalistas criam: "vilões, vítimas, histórias nas quais as pessoas reais em sua complexidade real e os perigos reais que elas e a sociedade como um todo enfrentam podem ser entrevistos apenas nas sombras" (Glassner, 2003: 104), propagando um efeito de medo sobre a realidade. Pesquisas minuciosas do sociólogo apontam como o medo é cultivado e quais setores se beneficiam com esse "comércio do medo". Para Glassner, os cultores do medo, utilizando práticas ilusionistas, fariam com que os problemas sérios continuem amplamente ignorados: desemprego, desigualdades sociais, entre outros. Dentre os beneficiados pela cultura do medo, explica Glassner, estão: advogados, segmentos da mídia, indústrias da segurança, políticos que ganham eleições propondo soluções para acabar com o medo.

Tendo como principal característica o sentimento coletivo de insegurança, provocado por percepções distorcidas da realidade -impostas por setores alarmistas interessados na obtenção de lucro ou no controle social-, a cultura do medo possui forte influência na formação do imaginário das pessoas. Dentre os "setores alarmistas", a mídia merece destaque, pois atinge grande público e assume importante papel na engrenagem da indústria cultural, disseminando ideias e sentimentos. Dessa forma, a mídia alcança o domínio da vontade, da inteligência, da emoção e do sentimento de significativa parcela da população.

\subsection{Espetacularização da política}

Em 1967, o pensador francês Guy Debord publica o livro Sociedade do Espetáculo, onde denunciava a tirania das imagens e a submissão alienante ao império da mídia. Os fundamentos da crítica de Debord são a vida cotidiana e a generalização do fetichismo da mercadoria, que invadiu todos os espaços da vida em sociedade. A mercantilização de tudo produz o espetáculo ininterrupto. Nele, o tempo, o espaço, o lazer, a comunicação, a cultura e tudo o mais é perpassado pela alienação. Para Debord (2004: 14), "o espetáculo não é um conjunto de imagens, mas uma relação social entre pessoas, mediada por imagens".

De acordo com Debord, no plano das técnicas, a imagem "construída" pode se tornar a principal ligação do indivíduo com o mundo real, que ele vivenciava por si mesmo, interagindo com as situações que defrontava em qualquer lugar que pudesse 
ir. Na sociedade espetacular não há mais espaço para vivermos nossas próprias experiências, são os modelos que vivem em nosso lugar: "tudo o que era vivido diretamente torna-se uma representação" (Debord, 2004: 13). As relações humanas são perpassadas pela lógica mercantil, e as pessoas são imersas em imagens que remetem unicamente às mercadorias. O consumo se apresenta como resposta ao vazio, ao não-lugar em que as pessoas aprisionadas pelo espetáculo são remetidas. Isso confere à imagem o poder de sustentar qualquer argumentação que se pretende impor, pois no plano da imagem é possível conectar as contradições do mundo, que jamais se reconciliariam na vida real.

O frenético fluxo de imagens produzido e continuamente repetido pelos meios de comunicação se encarrega de inverter, na mente dos indivíduos, o vivido pela imagem. Esse ritmo acelerado faz com que tudo se manifeste como perpétua surpresa arbitrária, deixando pouco ou nenhum tempo para a reflexão. Sem refletir, o indivíduo torna-se "espectador da vida", não consegue pensar ou entender seus atos.

Nesse contexto, não devemos esquecer que a mídia brasileira possui uma parcela de responsabilidade nada desprezível na construção de narrativas que "explicam" os fatos do mundo e a transformação da sociedade e, portanto, na elaboração de percepções e consensos sobre a política. O olhar propagado pela mídia nada tem em comum com a experiência própria do indivíduo, pois exibe um mundo ideal enquanto oblitera referenciais de espaço e tempo, essenciais à percepção do homem como ser histórico. Para Debord,

"A ideologia é a base do pensamento de uma sociedade de classes, no curso conflitante da história. Os fatos ideológicos nunca foram simples quimeras, mas a consciência deformada das realidades, e, como tais, fatores reais que exercem uma real ação deformante; tanto mais que a materialização da ideologia provocada pelo êxito concreto da produção econômica autonomizada, na forma do espetáculo, praticamente confunde com a realidade social uma ideologia que conseguiu recortar todo o real de acordo com seu modelo» (Debord, 2004: 137).

A dinâmica eleitoral brasileira favorece o estabelecimento de um debate político esvaziado de conteúdo e espetacularizado na forma. Durante as campanhas eleitorais, principalmente para cargos majoritários, os candidatos lançam acusações -sem compromisso com a comprovação- contra seus adversários, repercutindo na mídia toda sorte de agressão. Não raro, como no caso analisado, a própria mídia propaga sua "opinião", revelando um discurso agressivo e utilizando padrões de manipulação com apropriações do discurso do medo. Essa multiplicidade de vozes, acirramento de interesses nem sempre claros ao eleitor, e utilização de imagens que estimulam as "paixões" humanas contribuem para a despolitização da disputa eleitoral. 


\section{METODOLOGIA}

\subsection{Análise de discurso}

Este estudo utiliza-se da Análise de Discurso de linha francesa (doravante AD), que propõe várias metodologias para desvelar regularidades e mecanismos por meio dos quais se produzem e se interpretam a fala (escrita ou oral) em situações de comunicação. Os métodos da AD têm proporcionado o desvelamento de relações hegemônicas não aparentes nas manifestações comunicativas, mas que são passíveis de se apreender na dimensão discursiva.

O discurso político, durante o período eleitoral, sofre a coerção da formação discursiva a que pertence, exibindo uma situação de disputa que estabelece a figura do sujeito-candidato e seu oposto, o outro, adversário político. Dessa forma, faz-se necessária a investigação da construção do ethos próprio -do sujeito-candidato enunciador- bem como a produção do antiethos destinada à figura do adversário. Portanto, neste artigo, os conceitos de ethos e antiethos permitem reconhecer nos embates discursivos a utilização do discurso do medo para desconstrução da imagem dos opositores políticos.

Parte-se do princípio, como afirma Eni Puccinelli Orlandi, que a AD tem como propósito "a compreensão de como um objeto simbólico produz sentidos, como ele está investido de significância para e por sujeitos". Essa compreensão, ainda segundo a autora, "implica em explicitar como o texto organiza os gestos de interpretação que relacionam sujeito e sentido. Produzem-se assim novas práticas de leitura" (Orlandi, 2010: 26-27). Dessa forma, os dizeres não são apenas mensagens passíveis de decodificação, mas efeitos de sentidos produzidos em condições determinadas, e que deixam vestígios no modo como se diz,

«São pistas que ele aprende a seguir para compreender os sentidos aí produzidos, pondo em relação o dizer com sua exterioridade, suas condições de produção. Esses sentidos têm a ver com o que é dito ali, mas também em outros lugares, assim como com o que não é dito, e com o que poderia ser dito e não foi. Desse modo, as margens do dizer, do texto, também fazem parte dele» (Orlandi, 2010: 30).

Não existem sentidos "literais" arquivados em algum compartimento do cérebro e que "aprendemos" a utilizar. A constituição dos sentidos e dos sujeitos se dá em processos, onde coexistem os jogos simbólicos -o que não temos o controle- e o equívoco, por meio do trabalho da ideologia e do inconsciente. Dessa maneira, pode-se afirmar que as visões de mundo se materializam na linguagem em suas diferentes manifestações: a verbal, a visual, a gestual, etc. A maneira de pensar o mundo, numa dada época, subordina-se aos temas e figuras estabelecidos por essas visões de mun- 
do. Assim, a maior parte dos discursos ${ }^{2}$ produzidos numa formação social ${ }^{3}$ concreta repete esses temas e figuras. Com relação à formação discursiva ${ }^{4}$, Fiorin afirma que,

«Temos, então, que considerar a formação ideológica como uma visão de mundo, ou seja, o ponto de vista de uma classe presente numa determinada formação social, e a formação discursiva como o conjunto de temas e figuras que materializam uma dada formação ideológica» (Fiorin, 1988: 14).

Entende-se que o texto é também um lugar de manipulação consciente, onde o sujeito falante organiza recursos de expressão para veicular, da melhor maneira possível, determinados discursos. O sujeito de uma dada formação social tem na formação discursiva a matéria-prima para elaborar seus discursos. No geral, ele reproduz em seus discursos as figuras e os temas presentes nos discursos dominantes de uma dada época, num determinado espaço geográfico. Entende-se, então, que "o enunciador real sempre vocaliza as formações ideológicas existentes na formação social em que vive" (Fiorin, 1988: 16).

Embora seja depositário de várias Formações Discursivas (FD) presentes numa formação social concreta -dividida em classes sociais distintas-o enunciador, sendo um ser social, geralmente é suporte apenas da formação discursiva dominante, que materializa a formação ideológica ${ }^{5}$ dominante.

Por mais inocente que possa parecer qualquer enunciado pode ter um sentido político. De qualquer maneira, como ato de comunicação, o discurso político está mais relacionado aos atores que participam da cena política. Verdadeiro campo de batalha em que se trava uma guerra simbólica, a política visa estabelecer relações de dominação ou pactos de convenção. O discurso político objetiva, assim, influenciar as opi-

2 Discurso: é o efeito de sentido construído no processo de interlocução (opõe-se à concepção de língua como mera transmissão de informação) (Brandão, 2004: 106).

3 Formação social: caracteriza-se por um estado determinado de relações entre classes que compõem uma comunidade em um determinado momento de sua história. Estas relações estão assentadas em práticas exigidas pelo modo de produção que domina a formação social. A essas relações correspondem posições políticas e ideológicas que mantém entre si laços de aliança, de antagonismo ou de dominação (Brandão, 2004: 107).

4 Formação discursiva: conjunto de enunciados marcados pelas mesmas regularidades, pelas mesmas "regras de formação". A formação discursiva se define pela sua relação com a formação ideológica, isto é, os textos que fazem parte de uma formação discursiva remetem a uma mesma formação ideológica. A formação discursiva determina "o que pode e deve ser dito" a partir de um lugar social historicamente determinado. Um mesmo texto pode aparecer em formações discursivas diferentes, acarretando, com isso, variações de sentido (Brandão, 2004: 106-107).

${ }^{5}$ Formação ideológica: é constituída por um conjunto complexo de atitudes e representações que não são nem individuais, nem universais, mas dizem respeito, mais ou menos diretamente, às posições de classe em conflito umas com as outras (Harouche et al.). Cada formação ideológica pode compreender várias formações discursivas interligadas (Brandão, 204: 107). 
niões a fim de obter adesões às propostas que defende, ou rejeições aos projetos adversários.

«O discurso político não esgota, de forma alguma, todo o conceito político, mas não há política sem discurso. Este é constitutivo daquela. A linguagem é o que motiva a ação, a orienta e the dá sentido. A política depende da ação e se inscreve constitutivamente nas relações de influência social, e a linguagem, em virtude do fenômeno de circulação dos discursos, é o que permite que se constituam espaços de discussão, de persuasão e de sedução nos quais se elaboram o pensamento e a ação políticos. A ação política e o discurso político estão indissociavelmente ligados, o que justifica pelo mesmo raciocínio o estudo político pelo discurso» (Charaudeau, 2011: 39).

\subsection{Formação discursiva política eleitoral}

Na Formação Discursiva Política Eleitoral (FDPE) os sujeitos discursivos tentam fixar sentidos em um cenário de disputa. A finalidade é utilizar seus discursos para impor sua verdade ao maior número de eleitores, em um ambiente sempre ameaçado pela verdade do(s) adversário(s), estabelecendo um jogo de significações. Neste jogo, a imagem do candidato sofre constantemente a desconstrução e, por outro lado, se constrói pela desconstrução do seu Outro (adversários políticos). Característica marcante da política na contemporaneidade, o sujeito-candidato incorpora em seu discurso características da FD publicitária, que situa o candidato como um produto à venda. Por outro lado, esse discurso também é permeável por algumas características da FD política, que impõe um ideal social a ser partilhado. Nesse sentido, o sujeito-candidato deve inspirar admiração, confiança, além de convocar o eleitor para participar de sua verdade. Consequência dessa característica da política, na atualidade, acentua-se a tendência do eleitorado de eleger candidatos sob um enforque personalista, apoiando-se na imagem projetada no discurso do sujeito-candidato. Dessa forma, considera-se importante estudar os conceitos de ethos e antiethos na política contemporânea.

Na FDPE os candidatos - personagens políticos- se confrontam e estabelecem uma disputa com a finalidade de projetar a imagem de si. Quando um candidato profere em discurso "sou isto e não sou aquilo", está construindo um ethos para si e, simultaneamente, rejeitando um antiethos. Observa-se que a situação de disputa política eleitoral estabelece a figura do sujeito-candidato e seu oposto, o outro, adversário político. Simultânea à construção do ethos próprio -do sujeito-candidato enunciador-, a produção do antiethos é destinada à figura do adversário. Essa estratégia -da crítica indireta- reforça a valorização do ethos próprio. Entretanto, a falha no ritual discursivo pode deslizar, inconscientemente, o antiethos para o próprio sujeito político enunciante. 


\subsection{Ethos e antiethos}

De acordo com Charaudeau (2011: 115), "o ethos relaciona-se ao cruzamento de olhares: olhar do outro sobre aquele que fala, olhar daquele que fala sobre a maneira como ele pensa que o outro vê". Ainda segundo o autor, a construção da imagem do sujeito que fala se apoia ao mesmo tempo nos dados anteriores ao discurso, isto é, naquilo que se sabe a priori do locutor, e nos dados trazidos pela própria enunciação. Essa posição é sustentada a partir da identidade do sujeito falante, dividida em duas componentes. A primeira refere-se à identidade social do locutor, que legitima sua fala e lhe dá direito à palavra, "em função do estatuto e do papel que lhe são atribuídos pela situação de comunicação" (Charaudeau, 2011: 115). Na segunda, a figura daquele que enuncia é construída pelo sujeito (locutor), estabelecendo "uma identidade discursiva de enunciador que se atém aos papéis que ele se atribui em seu ato de enunciação, resultado das coerções da situação de comunicação que se impõe a ele e das estratégias que ele escolhe seguir" (Charaudeau, 2011: 115). Neste contexto, o sujeito, perante o olhar do outro, mostra-se com uma identidade social e psicológica socialmente atribuída, enquanto se esforça na construção de uma identidade discursiva para si. Dessa forma, nossas palavras adquirem sentido baseado no que dizemos e, também, no que somos. Essa dupla identidade -social e discursiva- ao se fundir resulta no que chamamos de ethos.

Ao pronunciar seu discurso, o orador deve construir uma imagem de si análoga a seu objetivo argumentativo, e levar em consideração a ideia que seu destinatário projeta dele, como afirma Haddad (2013: 148), "o ethos prévio ou pré-discursivo condiciona a construção do ethos discursivo e demanda a reelaboração dos estereótipos desfavoráveis que podem diminuir a eficácia do argumento". Dessa forma, a construção do ethos do discurso é afetada pela imagem previamente estabelecida, "Ionge de constituir um elemento exterior ao discurso, cuja análise não deve ser levada em conta, o ethos prévio está, ao contrário, estreitamente ligado ao ethos discursivo" (Haddad, 2013: 163). Essa noção é compartilhada por Amossi, para quem a imagem que o locutor constrói em seu discurso não é totalmente desvinculada da ideia prévia que se faz do locutor. Nesse sentido, Maingueneau (2008: 60) entende que, mesmo se o destinatário não souber nada sobre o ethos do locutor, "o simples fato de um texto pertencer a um gênero de discurso ou a certo posicionamento ideológico induz expectativas em matéria de ethos".

A imagem de si construída no discurso constitui a interação verbal, atuando decisivamente na "capacidade de o locutor agir sobre seus alocutários" (Amossi, 2013: 137). Por outro lado, para que essas estratégias sejam reconhecidas pelo auditório, sendo consideradas legítimas, "é preciso que sejam assumidas em uma doxa, isto é, 
que se indexem em representações partilhadas" (Amossi, 2013: 125). Assim, o orador pode trabalhar com expectativa de reconhecimento de seu discurso pelos ouvintes.

Dependendo do ponto de vista -seja do locutor ou do destinatário- a noção de ethos pode remeter a coisas muito diferentes e, assim, o ethos pretendido pode não corresponder ao ethos produzido. Maingueneau afirma que,

"O ethos de um discurso resulta de uma interação de diversos fatores: ethos prédiscursivo, ethos discursivo (ethos mostrado), mas também de fragmentos do texto em que o enunciador evoca sua própria enunciação (ethos dito) [...] A distinção entre ethos dito e ethos mostrado inscreve-se nos extremos de uma linha contínua, já que é impossível definir uma fronteira nítida entre o "dito" e o "mostrado". Ethos efetivo, o que tal ou qual destinatário constrói, resulta da interação dessas diversas instâncias, cujo peso respectivo varia segundo os gêneros de discurso» (Maingueneau, 2008: 71).

Dessa forma, ao constituir um ethos próprio, o candidato investe direta ou indiretamente na produção do antiethos à figura do adversário. Essa estratégia de realizar a crítica indireta do oponente reforça a valorização do ethos próprio. No entanto, a falha no ritual discursivo pode deslizar, inconscientemente, o antiethos para o próprio sujeito político enunciante, construindo uma imagem negativa do candidato.

\section{DISCURSO DO MEDO E ELEIÇÕES NO BRASIL}

Em todas as disputas eleitorais para Presidente da República, desde o fim da ditadura militar o discurso do medo tem sido utilizado como estratégia de campanha. Em 1989, Fernando Collor ganhou apostando no medo: "Se Lula vencer, irá confiscar a poupança". Os principais argumentos utilizados para espalhar o medo entre os eleitores foram: ateísmo, comunismo, confisco de propriedades, anarquia.

Em 1994, Fernando Henrique ganhou o pleito com larga vantagem -e a esperançade manutenção do recém-criado Plano Real ${ }^{6}$. Dentre as mensagens que estimulavam o medo contra o principal adversário, Lula do Partido dos Trabalhadores (PT), estavam: volta da inflação, sectarismo/radicalismo do PT, falta de experiência, falta de estudo.

6 O Plano Real foi um programa do governo brasileiro com o objetivo de estabilização e reformas econômicas, iniciado em 27 de fevereiro de 1994 com a publicação da medida provisória número 434. Tal medida provisória instituiu a Unidade Real de Valor (URV), estabeleceu regras de conversão e uso de valores monetários, iniciou a desindexação da economia, e determinou o lançamento de uma nova moeda, o Real. O programa foi a mais ampla medida econômica já realizada no Brasil e tinha como objetivo principal o controle da hiperinflação que assolava o país. Utilizou-se de diversos instrumentos econômicos e políticos para a redução da inflação que chegou a $46,58 \%$ ao mês em junho de 1994, época do lançamento da nova moeda. A idealização do projeto, a elaboração das medidas do governo e a execução das reformas econômica e monetária contaram com a contribuição de vários economistas, reunidos pelo então Ministro da Fazenda Fernando Henrique Cardoso (Fonte: Wikipédia). 
Na reeleição, em 1998, Fernando Henrique do Partido da Social Democracia Brasileira (PSDB) ganhou no primeiro turno com o discurso do medo, tendo a volta da inflação, boatos de fechamento de igrejas e incapacidade como motivos para refutar novamente o adversário Lula, "o medo novamente é utilizado para justificar a necessidade de manter a política como estava, pois mudando o governante poderíamos provocar um caos político e, principalmente um caos econômico no país" (Chaia, 2004: 37).

Em 2002, José Serra, candidato do governo também utilizou o discurso do medo ao enfrentar o persistente candidato Lula. O preconceito foi novamente utilizado contra Lula, acusado de despreparado e aventureiro. Também o medo da instabilidade econômica retorna à pauta de campanha, intimidando os eleitores. A atriz Regina Duarte declara no primeiro programa do Horário Gratuito Político Eleitoral (HGPE) de José Serra: "Estou com medo de que o país perca a estabilidade tão duramente conquistada", no caso de vitória de Lula. Neste pleito, após quatro derrotas consecutivas, Lula vence a eleição: "Certas estratégias de campanha não dão o resultado esperado. Desta vez, o medo não foi assimilado pelo eleitorado" (Chaia, 2004: 43).

Em 2006, os opositores retomam as críticas à área econômica colocando em dúvida a capacidade do presidente Lula -candidato à reeleição- de cumprir as promessas de crescimento do Produto Interno Bruto (PIB), redução de impostos e dos gastos públicos. Além disso, a questão ética surge como opção de ataque dos adversários do presidente, após a divulgação dos fatos que ficou conhecido como "escândalo do mensalão" 7 . O discurso do medo é reforçado pela adoção de teses moralistas contra o presidente,

«A necessidade maior deixou de ser apenas a manutenção da estabilidade econômica ou a inserção do país na modernidade, via liberalismo, mas também o (clichê) "banho de ética", que só seria possível por meio da derrota, nas urnas, do presidente e seu partido» (Nogueira, 2008: 89).

Mais uma eleição polarizada, com ataques mútuos entre os principais candidatos, em 2010 o que diferenciou as campanhas foi a intensidade dos ataques durante a propaganda eleitoral. Enquanto a campanha de Dilma trabalhou mais o nível do desejo do destinatário da mensagem (promessas), seu principal adversário, José Serra, apresentou uma campanha com intenso uso da intimidação: o eleitor deveria escolhê-lo por medo. Para Katia Saisi,

\footnotetext{
Mensalão é o nome dado ao escândalo de corrupção política mediante compra de votos de parlamentares no Congresso Nacional do Brasil, que ocorreu entre 2005 e 2006. O caso teve como protagonistas alguns integrantes do governo do então presidente Luiz Inácio Lula da Silva, membros do PT e de outros partidos (PTB, PP e PL), sendo objeto da ação penal de número 470, movida pelo Ministério Público no Supremo Tribunal Federal (Fonte: Wikipédia).
} 
«O que mais prevaleceu nos discursos midiáticos, seja na propaganda dos candidatos, seja na imprensa, foi a lógica do complô: escândalos, acusações mútuas, ameaças, desqualificação do projeto adversário. A "estratégia do medo" esteve presente durante toda a campanha. Após a representação da ocupação do poder por parte do povo na figura de um presidente operário oriundo das classes mais pobres da população, as lutas simbólicas passam a se dar no campo do gerenciamento da res pública. Privilegiase, assim, o discurso da capacidade tecnocrática e busca-se apontar os interesses privados dos grupos políticos, enfatizando a imagem do complô» (Saisi, 2013: 25-26).

Nas últimas eleições para Presidente da República do Brasil, em 2014, o discurso do medo retorna, utilizado de maneira direta e indireta nas campanhas dos presidenciáveis com maiores chances de vencer o pleito, independente da ideologia políticopartidária.

\section{O MEDO NA DISPUTA ELEITORAL DE 2014}

Para composição dos recortes -sequências discursivas- utilizados neste artigo, orientou-se pela proposta de Orlandi (2010) que postula que essa delimitação não segue critérios empíricos, mas teóricos ${ }^{8}$. Assim, o corpus se delimita à prática discursiva dos quatro principais candidatos à Presidência da República do Brasil em 2014: Eduardo Campos, Marina Silva, Aécio Neves e Dilma Rousseff, publicados em veículos de comunicação (impressos e/ou eletrônicos) relevantes no contexto social brasileiro.

A justificativa para a constituição do corpus deve-se, principalmente, pelo destaque que os discursos selecionados obtiveram na mídia brasileira, pautando a grande imprensa e meios eletrônicos de comunicação. Por outro lado, a acirrada disputa eleitoral, identificada pelas intenções de voto apuradas por importantes institutos de pesquisa, possibilitou uma escalada nos ataques entre os candidatos, bem como a apropriação do discurso do medo pelas principais candidaturas.

Durante a campanha eleitoral de 2014, o PSDB e seu candidato Aécio Neves atacam as boas relações do Brasil com o governo cubano, fazendo ressurgir o fantasma do comunismo na tentativa de tirar votos da adversária: Dilma Rousseff (PT). Para tanto, o partido publicou na sua página no Facebook uma animação de um minuto e dezoito segundos, intitulada "Os Monstros da Dilma" ${ }^{9}$. Na animação, figuram personagens criados pelo PSDB em alusão ao que o partido considerava "problemas do

\footnotetext{
8 Sabe-se que a escolha de um objeto a ser analisado, utilizando-se a fundamentação teórica da Análise de Discurso, não pode ser aleatória. Dessa forma, os recortes têm que vir com os objetivos propostos pelo analista. Conforme Orlandi (2010), o objeto discursivo não é dado, ele supõe um trabalho inicial do analista. Num primeiro momento de análise, é preciso converter o corpus bruto, empírico em um objeto teórico.

9 PSDB (2014): "Os monstros de Dilma", Facebook. Disponível em https://goo.gl/On9ApS. Consultado em 21 de fevereiro de 2015.
} 
governo petista". Ao lado da "Fantasmagórica Corrupção" e do "Jurássico PAC" aparece o personagem "Godzilla Cubano", uma figura pré-histórica exibindo uma banda$n \mathrm{a}^{10} \mathrm{com}$ a bandeira cubana. Com isso estimularam o medo do comunismo, aproveitando uma discussão comum nos debates do submundo da internet, e fizeram surgir inúmeras teorias conspiratórias, como as de que os médicos cubanos -contratados pelo Programa Mais Médicos ${ }^{11}$ - seriam guerrilheiros que viriam ao Brasil perpetrar um golpe comunista. O antiethos produzido contra Dilma propaga o medo do comunismo, combatido de longa data por forças conservadoras e de direita no Brasil ${ }^{12}$.

Aécio Neves também investiu contra a imagem da candidata Marina Silva, utilizando o discurso do medo, principalmente quando esta apareceu à frente do candidato do PSDB nas intenções de voto, segundo levantamento dos principais Institutos de Pesquisa. Em entrevista à rádio Central Brasileira de Notícias (CBN), durante a campanha, afirmou: "A candidatura de Marina tem suas virtudes, eu as respeito, mas traz também um conjunto de contradições muito grandes, ela fez toda a sua trajetória política no PT (...) O Brasil não aguenta uma incerteza no seu horizonte, uma nova aventura" $^{\prime 13}$. O antiethos produzido contra Marina Silva explora a insegurança e o medo de suas contradições políticas.

Durante almoço com empresários no Paraná, o ex-presidente Lula (PT) teria dito que estava preocupado com a possibilidade de se repetir em 2014, o que ocorreu em 1989, quando um jovem candidato "desconhecido" que venceu as eleições. Referia-se a Fernando Collor de Mello, presidente brasileiro que sofreu impeachment por suspeita de corrupção. Em resposta, o governador de Pernambuco, pré-candidato à presidência pelo Partido Socialista Brasileiro (PSB), Eduardo Campos, respondeu em um blog de notícias" : "Toda vez que o país pede mudanças, alguns políticos tentam colocar o medo no coração do povo. Mas desta vez, como aconteceu em 2002, a espera-

${ }^{10}$ A bandana é um ornato para a cabeça. É feita com um lenço de formato quadrado ou triangular que é dobrado diversas vezes, formando uma tira que cobre a testa, ou até mesmo o topo inteiro da cabeça.

${ }^{11}$ O Programa Mais Médicos faz parte de um amplo pacto de melhoria do atendimento aos usuários do Sistema Único de Saúde, que prevê investimento em infraestrutura dos hospitais e unidades de saúde, além de levar mais médicos para regiões onde não existem profissionais. A Lei no 12.871 , de 22 de outubro de 2013 institui o Programa Mais Médicos, altera as Leis no 8.745, de 9 de dezembro de 1993, e no 6.932, de 7 de julho de 1981, e dá outras providências (Fonte: Ministério da Saúde - MS).

12 PRAGMATISMO POLítico (2014): “Aécio usa 'medo do comunismo' contra Dilma”, Pragmatismo Político, 22 de outubro de 2014. Disponível em https://goo.gl/5Csbeh. Consultado em 21 de fevereiro de 2015.

VENCESLAU, P. e LOPES, E. (2014): "Tática do medo pode ajudar candidatura de Aécio, diz marqueteiro", Estadão, 9 de junho de 2014. Disponível em https://goo.gl/AEFCHL. Consultado em 21 de fevereiro de 2015.

${ }^{13}$ G1 (2014): “'Nova aventura não faria bem ao país, diz Aécio sobre cenário eleitoral”, G1, 3 de setembro de 2014. Disponível em https://goo.gl/tCwgmd. Consultado em 2 de março de 2015.

14 RODRIGUES, F. (2014): "Tentam colocar 'medo no povo', diz Eduardo Campos", Blog do Fernando Rodrigues, 19 de março de 2014. Disponível em https://goo.gl/g4yxCZ. Consultado em 21 de fevereiro de 2015. 
nça vai vencer o medo". A resposta de Campos contém referências históricas das disputas eleitorais do próprio Lula. Ao utilizar a frase "a esperança vai vencer o medo", o governador de Pernambuco usa uma ideia-força do utilizada pelo PT durante a primeira campanha presidencial que levou Lula ao Planalto, em $2002^{15}$. O antiethos denunciado por Eduardo Campos -proferido por Lula- propaga o medo ao "novo" e às mudanças representadas pelo jovem político.

Já a candidata também pelo PSB, Marina Silva -que assumiu a candidatura após a morte de Eduardo Campos-, afirmou em entrevista ao portal G1 da Rede Globo de Televisão que a candidata à reeleição, Dilma Rousseff estava querendo "ressuscitar o medo" na campanha eleitoral ${ }^{16}$. Ao ser questionada sobre a agressividade na campanha eleitoral, Marina repetiu o bordão usado na campanha de 2002 pelo expresidente Luiz Inácio Lula da Silva, afirmando que "a esperança venceu o medo"17. A candidata do PSB também afirmou que a população brasileira acredita e confia na democracia, e não se deixa levar pelo discurso do medo. Além disso, expos sua surpresa por justamente o PT, que sempre foi vítima desse discurso, ter ressuscitado o medo como estratégia de campanha. Dentre as ações perpetradas para criar um clima de medo em torno de sua candidatura, segundo Marina Silva, estão: a afirmação da presidente Dilma de que o programa de governo de Marina "reduziria a pó" a política industrial; a declaração do então Ministro da Fazenda, Guido Mantega, de que o programa de Marina poderia "paralisar a economia"18; a comparação de Marina aos ex-presidentes Jânio Quadros e Fernando Collor, que não concluíram seus mandatos -Jânio renunciou e Collor sofreu impeachment- em programa de TV da campanha de Dilma no HGPE. Esses ataques intensificaram-se após Marina Silva ser apontada pelos Institutos de Pesquisa como favorita num eventual segundo turno contra a presidente Dilma. O antiethos denunciado por Marina Silva, e atribuídos à estratégia de campanha de Dilma, propaga o medo do caos econômico e ausência de sustentação políticopartidária no congresso Nacional, caso Marina vencesse as eleições.

Temendo a derrota, após sucessivas quedas nos índices de intenção de voto, os responsáveis pela campanha do Partido dos Trabalhadores adotaram o discurso do

${ }^{15}$ Durante a campanha eleitoral de 2002, o PSDB usou a atriz Regina Duarte para dizer na TV que tinha medo do que poderia acontecer se Lula fosse eleito presidente. Para combater o discurso do medo, o publicitário Duda Mendonça -responsável pela campanha de Lula- inventou o bordão "a esperança vai vencer o medo". Funcionou, e o PT ganhou a eleição -o segundo colocado foi o tucano José Serra (PSDB)-.

${ }^{16}$ G1 (2014,): “Dilma quer ressuscitar o medo na campanha, afirma Marina Silva”, G1, 3 de setembro de 2014. Disponível em https://goo.gl/SOuDcf. Consultado em 22 de fevereiro de 2015.

17 ROLIM, M. (2014,): “A esperança e o medo", Marcos Rolim, 13 de setembro de 2014. Disponível em https://goo.gl/VKxO8y. Consultado em 3 de março de 2015.

${ }^{18}$ G1 (2014): “Programa de Marina Silva pode paralisar a economia, diz Mantega”, G1, 2 de setembro de 2014. Disponível em https://goo.gl/CQlpr7. Consultado em 3 de março de 2015. 
medo como estratégia. A presidente e candidata à reeleição Dilma Rousseff foi apresentada como única garantia de que as "conquistas do povo" não serão tiradas. Simultaneamente, assume um discurso do medo, insinuando que os adversários, se chegarem ao poder, eliminariam os benefícios conquistados com os governos petistas: Bolsa-família ${ }^{19}$, PROUNI $^{20}$, Mais-médicos. Essas mensagens foram inseridas no programa partidário e anúncios publicitários da campanha eleitoral, e de forma indireta, nos discursos da candidata Dilma. Neste caso, o antiethos atribuído aos seus adversários propaga, principalmente, o medo da perda de benefícios e conquistas sociais adquiridos durante os governos petistas.

\section{CONCLUSÃO}

Ao construir sua própria imagem (ethos), os candidatos à Presidência da República atuaram, simultaneamente, na desconstrução da imagem dos adversários, criando para estes um antiethos, sempre sob as coerções próprias da FDPE. Dessa forma, a FDPE determinou o discurso do candidato, bem como a maneira como o discurso do medo deveria ser introduzido. Da mesma maneira, a FDPE determina como e quando o candidato deve expor os agentes causadores do medo atribuídos aos adversários. Entende-se que, as falhas na construção do ethos próprio ou do antiethos dos adversários podem estar entre as causas da derrota eleitoral.

Nas sequências discursivas analisadas neste trabalho -pronunciadas pelos principais candidatos à Presidência da República do Brasil em 2014-, observa-se que, embora tenha concentrado os ataques individuais aos principais opositores, o discurso da candidata Dilma tenta criar um antiethos genérico a todos adversários, levantando suspeitas de eliminação dos programas sociais instituídos pelos governos petistas, caso seus oponentes vencessem o pleito. Olhando simplesmente para o resultado das eleições, pode-se afirmar que a apropriação do discurso do medo, juntamente às

${ }^{19}$ O Bolsa Família é um programa de transferência direta de renda que beneficia famílias em situação de pobreza e de extrema pobreza em todo o país. O Bolsa Família integra o Plano Brasil Sem Miséria, que tem como foco de atuação os milhões de brasileiros com renda familiar per capita inferior a R\$় 77 mensais e está baseado na garantia de renda, inclusão produtiva e no acesso aos serviços públicos. A gestão do programa instituído pela Lei 10.836/2004 e regulamentado pelo Decreto no 5.209/2004, é descentralizada e compartilhada entre a União, estados, Distrito Federal e municípios (Fonte: Ministério do Desenvolvimento Social - MDS).

${ }^{20}$ O Programa Universidade para Todos - PROUNI tem como finalidade a concessão de bolsas de estudo integrais e parciais em cursos de graduação e sequenciais de formação específica, em instituições de ensino superior privadas. Criado pelo Governo Federal em 2004 e institucionalizado pela Lei no 11.096, em 13 de janeiro de 2005 oferece, em contrapartida, isenção de tributos àquelas instituições que aderem ao Programa. Dirigido aos estudantes egressos do ensino médio da rede pública ou da rede particular na condição de bolsistas integrais, com renda familiar per capita máxima de três salários mínimos (Fonte: Ministério da Educação e Cultura - MEC). 
demais ações da campanha de Dilma, foi exitosa. Por outro lado, Aécio Neves também utilizou o discurso do medo para "amedrontar" os eleitores, insinuando a possibilidade da "invasão comunista" no Brasil, se Dilma vencesse. Mesmo que seu discurso estivesse longe da realidade dos fatos, pode-se dizer que sua apropriação do discurso do medo também foi exitosa, pois o levou ao segundo turno do pleito onde teve uma disputa acirradíssima com a adversária, candidata à reeleição. Já os candidatos Eduardo Campos e Marina Silva preferiram denunciar a estratégia do discurso do medo para desconstrução da imagem de que estavam sendo vítimas. Não é possível nenhuma conclusão em relação ao êxito/fracasso do candidato Eduardo Campos, devido ao seu falecimento. Em contrapartida, observa-se que a candidata Marina Silva não conseguiu êxito em livrar-se das acusações e superar o medo de sua candidatura, introjetado na mente dos eleitores. Mesmo participando pela segunda vez consecutiva de eleição majoritária para Presidente da República, e contando com uma base eleitoral relativamente consolidada, a candidata viu os indicadores de intenção de voto em sua chapa despencar após os ataques e acusações -que exploraram com intensidade o discurso do medo- não conseguindo reagir e reverter o cenário.

O discurso do medo identificado na campanha eleitoral de 2014 refere-se, entre outras, à ameaça de retorno do cidadão a uma situação pior do que a vivida por ele na atualidade, bem como ameaça de perdas de benefícios e conquistas sociais. Em segundo plano, o risco do retorno da inflação e desemprego. Sendo que, as ameaças às necessidades básicas do cidadão despertam os impulsos de conservação do indivíduo e, consequentemente, instalam o medo nos eleitores, favorecendo a utilização de mecanismos de manipulação no discurso político. Assim, a disposição conservadora do indivíduo, antes mesmo de manifestar-se no plano racional, determina comportamentos de defesa e autoproteção, revelando seus temores.

Se como afirma Hobbes, o medo foi o produtor de racionalidade que permitiu a saída do homem da barbárie, a gênese e necessidade da racionalidade instrumental voltada para a dominação da natureza, segundo Adorno e Horkheimer, aparece como reação ao sentimento do medo. Por outro lado, a relação do medo com a razão, descrita por Rancière, permite três diferentes atitudes: a fuga, a recusa ou a interação com essa paixão humana, sendo essa última, a interação, a atitude identificada nas sequências discursivas analisadas nesse trabalho.

Nesse sentido, os estímulos de medo propagados durante as campanhas eleitorais trabalham com a dimensão instintiva dos eleitores, limitando o espaço para reflexão. Em contrapartida, as apropriações do discurso do medo, espetacularizadas no discurso dos candidatos, aprofundam o processo de manipulação do indivíduo e fragilizan- 
do da noção de política, além de estimular a cultura do medo, o chamado medo secundário de Bauman.

Numa democracia, as eleições significam um ritual periódico de lembrança da delegação de soberania em troca de segurança. Porém, num contexto de alienação cívica, em que o espaço público se esvazia e o discurso do medo se expande, a capacidade da sociedade de determinar o bem público, mobilizando-se para tal, se atrofia, espetacularizando a política.

Conclui-se que, no atual contexto político-eleitoral brasileiro o discurso do medo é utilizado de maneira generalizada pelos candidatos e partidos, independentemente do posicionamento ideológico. Verifica-se que, mesmo os chamados "partidos progressistas", identificados com ideologias mais à esquerda no espectro político brasileiro, quando no poder desenvolvem discursos conservadores, contrários à mudança.

\section{BIBLIOGRAFIA}

ADORNO, T. \& HORKHEIMER, M. (1985): Dialética do Esclarecimento. Rio de Janeiro: Jorge Zahar.

AMOSSI, R. (org.) (2013): Imagens de si no discurso: a construção do ethos. São Paulo: Contexto.

BAUMAN, Z. (2006): Medo líquido. Rio de Janeiro: Zahar.

BOBBIO, N., MATTEUCI, N. e PASQUINO, G. (1995): Dicionário de política. Brasília: UNB.

BRANDÃO, H. H. N. (2004): Introdução à análise do discurso. São Paulo: Unicamp.

CHAIA, V. (2004): "Eleições no Brasil: o medo como estratégia política", in Rubim, A. A. C.: Eleições presidenciais em 2002 no Brasil. São Paulo: Hacker, pp. 29-52.

CHAUÍ, M. (2009): "Sobre o medo", in Novaes, A. (org.): Os sentidos da paixão. São Paulo: Companhia das Letras, pp. 35-75.

CHARAUDEAU, P. (2011): Discurso político. São Paulo: Contexto.

CICERI, M. R. (2004): O medo. São Paulo: Paulinas.

COUTINHO, J. P. (2014): As ideias conservadoras. São Paulo: Três Estrelas.

DEBORD, G. (2004): A sociedade do espetáculo. Rio de Janeiro: Contraponto.

DELUMEAU, J. (2007): "Medos de ontem e de hoje", in Novaes, A. (org.): Ensaios sobre o medo. São Paulo: Senac, pp. 39-52.

DELUMEAU, J. (2009): História do medo no ocidente. São Paulo: Companhia das Letras.

FIORIN, J. L. (1988): O regime de 1964: discurso e ideologia. São Paulo, Atual. 
GLASSNER, B. (2003): Cultura do medo. São Paulo: Francis.

HADDAD, G. (2013): "Ethos prévio e ethos discursivo: o exemplo de Romain Rolland", in Amossi, R. (org.): Imagens de si no discurso: a construção do ethos. São Paulo: Contexto, pp. 145-166.

HOBBES, T. (1979): Leviatã ou matéria, forma e poder de um estado eclesiástico e civil. São Paulo: Abril Cultural.

KEHL, M. R. (2007): "Elogio do medo", in Novaes, A. (org.): Ensaios sobre o medo. São Paulo: Senac, pp. 89-110.

MAINGUENEAU, D. (2008): Cenas da enunciação. São Paulo: Parábola.

MIRA Y LÓPEZ, E. (1996): Quatro gigantes da alma. Rio de Janeiro: José Olympio.

NOGUEIRA, J. (2008): "Eleições 2006: o discurso do medo e sua variação", Aurora, no 3, pp. 86-102. Disponível em https://goo.gl/9dp2fd. Consultado em 14 de julho de 2015.

NOVAES, A. (2007): "Políticas do medo", in Novaes, A. (org.): Ensaios sobre o medo. São Paulo: Senac, pp. 9-16.

RANCIÈRE, J. (2007): "Do medo ao terror", in Novaes, A. (org.): Ensaios sobre o medo. São Paulo: Senac, pp. 53-71.

SAISI, K. (2013): "Mídia e construção de mitos políticos na campanha presidencial brasileira", in VV.AA.: Anais do V Congresso da Compolítica. Disponível em https://goo.gl/nVfVXq. Consultado em 26 de junho de 2015.

SILVA, A. O. (2010): "O pensamento conservador", Revista Espaço Acadêmico, vol. 9, no 107, pp. 53-55. Disponível em https://goo.gl/sJhV5D. Consultado em 14 de julho de 2015.

THOMPSON, J. B. (1998): Mídia e Modernidade. Petrópolis: Vozes.

Vanderlei de Castro EZEQuiel é mestre em Comunicação pela Faculdade Cásper Líbero; membro do grupo de pesquisa "Comunicação e Sociedade do Espetáculo» vinculado ao programa de Pósgraduação da Faculdade Cásper Líbero e registrado no CNPq (Conselho Nacional de Desenvolvimento Científico e Tecnológico). Correo electrónico: vander.ce@gmail.com. 